\title{
Differentiation of mild keratoconus from corneal warpage according to topographic inferior steepening based on corneal tomography data
}

\author{
Diferenciação de ceratocone leve e deformação corneana por lente de contato com encurvamento inferior \\ baseado em dados da tomografia de córnea
}

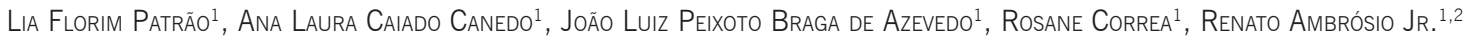

\begin{abstract}
We report two cases of suspicious asymmetric bow tie and inferior steepening on topographic evaluations with reflection (Placido) and projection (Scheimpflug). Rotating Scheimpflug corneal and anterior segment tomography (Oculus Pentacam HR, Wetzlar, Germany ${ }^{\circledR}$ was performed in the first case, with a maximal keratometric value (Kmax) of 43.2 D and an overall deviation value from the Belin/Ambrósio Enhanced Ectasia Display (BAD-D) of 1.76, which was observed in the study eye (OD). BAD-D was 6.59 in the fellow eye, which had clinical findings that were consistent with keratoconus stage 2. The second case presented with a Kmax of $45.3 \mathrm{D}$ and BAD-D of 0.76 in OD and 1.01 in OS. This patient had discontinued wearing soft contact lens less than 1 day prior to examination. Corneal tomographic data enabled us to distinguish mild or forme fruste keratoconus from contact lens-induced corneal warpage, and similar findings were observed on curvature maps.
\end{abstract}

Keywords: Tomography; Corneal topography; Keratoconus; Ectasia/diagnosis; Corneal diseases

\section{RESUMO}

O presente estudo tem por objetivo relatar dois casos suspeitos que apresentam bow tie assimétrico e encurvamento inferior nas avaliações topográficas de reflexão (Placido) e projeção (Scheimpflug). A tomografia de córnea e segmento anterior com o sistema Scheimpflug (Oculus Pentacam HR, Wetzlar, Alemanha) ${ }^{\circledR}$ mostrou no primeiro caso, a ceratometria máxima (Kmax) de 43,2 D e o valor D no Belin/ Ambrósio Enhanced Ectasia Display (BAD-D) de 1,76 no olho estudado (OD). $O$ olho contralateral apresentava BAD-D de 6,59 e achados clínicos compativeis com ceratocone (KC) grau 2. O segundo caso apresentava Kmax de 45,3 De BAD-D de 0,76 em OD e 1,01 em OS. Este paciente havia interrompido o uso de lentes de contato gelatinosas 1 dia antes do exame. A avaliação tomográfica avançada nos permitiu distinguir ceratocone leve ou subclínico de warpage induzido por lentes de contato, enquanto resultados semel hantes foram observados em mapas de curvatura anterior.

Descritores: Tomografia; Topografia de córnea; Ceratocone; Ectasia/diagnóstico; Córnea/patologia; Relato de casos

\section{INTRODUCTION}

Analysis of the topographic pattern of the front or anterior corneal surface has utility in identifying mild or sub-clinical ectatic corneal disease ${ }^{(1)}$. Placido disk-based corneal topography analyzes the reflex from the corneal surface, thereby enabling mathematic representations of the anterior (front) corneal surface topography ${ }^{(2)}$. However, it does not provide information regarding the posterior corneal surface nor corneal thickness. It is believed that many ectatic disorders may present as changes to the posterior surface before changes are observed on the anterior corneal surface ${ }^{(3)}$.

Corneal tomography, through the provision of anterior and posterior elevation maps, enables the profile of pachymetric progression and indices, such as Ambrósio Relational Thinnest (ART) and the parameter deviation (D), to be measured and is useful in screening and differentiating between normal and diseased corneas or those susceptible to disease.

The tomographic approach of three-dimensional reconstruction of the corneal structure provides a more complete overview of corneal shape ${ }^{(4)}$ and enables the assessment of changes to the posterior cornea and/or corneal thickness map, which are earlier indicators of ectatic change ${ }^{(5)}$.
Keratoconus (KC) is a bilateral non-inflammatory ectatic disease that is characterized by progressive thinning and protrusion of the cornea. In the majority of cases, corneal topography is characterized by focal thinning over the peripheral or midperipheral zone, which coincides with the location of conical protrusion ${ }^{(1)}$. The term forme fruste keratoconus (FFKC), first described by Amsler in 1961 and then by Klyce, should be used to define the contralateral eye in asymmetric KC as being "an incomplete, abortive, or unusual form of a syndrome or disease"(6).

Corneal warpage is a reversible contact lens-induced change in corneal shape, which should be distinguished from true corneal ectatic disorder. Corneal warpage may be due to either mechanical action of the lens on the cornea or a combination of mechanical and metabolic changes related to the corneal epithelium ${ }^{(7)}$. Clinical signs of corneal warpage include changes in refractive error, a decrease in corrected visual acuity, and steepening or flattening of the corneal curvature. However, progressive thinning is not associated with corneal warpage. Partial or complete reversal of corneal warpage typically occurs after discontinuing contact lens wear ${ }^{(8)}$. The waiting period for contact lens-induced corneal warpage to stabilize significantly varies among individuals and contact lens type. Sequential examinations of corneal topography in contact lens wearers can be performed to evaluate corneal warpage regression.
Funding: No specific financial support was available for this study.

Disclosure of potential conflicts of interest: Dr. Ambrósio is a consultant for Oculus, Wetzlar, Germany ${ }^{\circledR}$. The other authors have no potential conflicts of interest to disclose.

Corresponding author: Lia Florim Patrão. Rua Conde de Bonfim, no 211/712 - Rio de Janeiro, RJ - 20520-050 - Brazil - E-mail: draliapatrao@gmail.com 
This case report aims to demonstrate the differentiation of these two clinical conditions, which present with similar topographic imaging findings, using a comprehensive corneal tomographic evaluation.

\section{CASE 1}

A 31-year-old woman with a previous diagnosis of keratoconus in the left eye returned to our clinic complaining of progressive loss of visual acuity in the same eye. The patient's uncorrected visual acuity (UCVA) was 20/40 in the right eye (OD) and 20/400-1 in the left eye (OS). Her best-corrected visual acuity (BCVA) was 20/20-1 (sph -1.00 cyl-0.50@ @0) in OD and 20/25-1 (sph-0.50 cyl-4.50@ 135) in OS.

The central corneal thickness in OD and OS were $528 \mu \mathrm{m}$ and $494 \mu \mathrm{m}$, respectively. Anterior corneal curvature measurement using Pentacam ${ }^{\circledR}$ revealed an inferior steepening in the studied eye (OD) and $\mathrm{KC}$ stage 2 in OS (Figure 1A). The maximal keratometric value (Kmax) was 43.2 and Ambrósio's relational thickness maximum (ART Max) was 284 in OD, under the cut-off value used to define keratoconus. The deviation value from the Belin/Ambrósio Enhanced Ectasia Display (BAD-D) was 1.76 in OD, which was above the cut-off value for forme fruste keratoconus (Figure 1 B). The patient was diagnosed with
KC stage 2 in OS on the basis of the corneal topography classification proposed by Amsler according to a Kmax of 51.3 D, ART Max of 164, and BAD-D of 6.59 (Figure 1 C) on corneal tomography.

\section{CASE 2}

A 33-year-old male who used soft contact lens visited our clinic to enquire about refractive surgery. He had removed his contact lenses 10 min prior to the appointment. The patient's UCVA was finger counting at 1 meter in both eyes. His BCVA was 20/20 (sph -7.50 cyl -0.50 @ 175) in OD and 20/20 (sph-7.25 cyl-0.50 @ 31) in OS. The central corneal thickness was $528 \mu \mathrm{m}$ and $538 \mu \mathrm{m}$ in OD and OS, respectively.

The patient presented with topographic alteration in both eyes, which is similar to the studied eye in the case presented above (Case $1, \mathrm{OD})$. The front sagittal curvature on Pentacam ${ }^{\circledR}$ demonstrated a bilateral inferior steepening with a Kmax in OD of 45.3D and in OS of 45.0D (Figure $2 \mathrm{~A}$ ). Tomographic evaluation demonstrated normal anterior and posterior curvature. Pachymetric progression indices were normal. ART Max calculation in OD was 459 and in OS was 432, which was above the cut-off value for KC in both eyes. BAD-D was 0.76 in OD and 1.01 in OS, under the cut-off value of normality (Figures $2 \mathrm{~B}$ and $\mathrm{C}$ ).

\section{A OCULUS - PENTACAM}

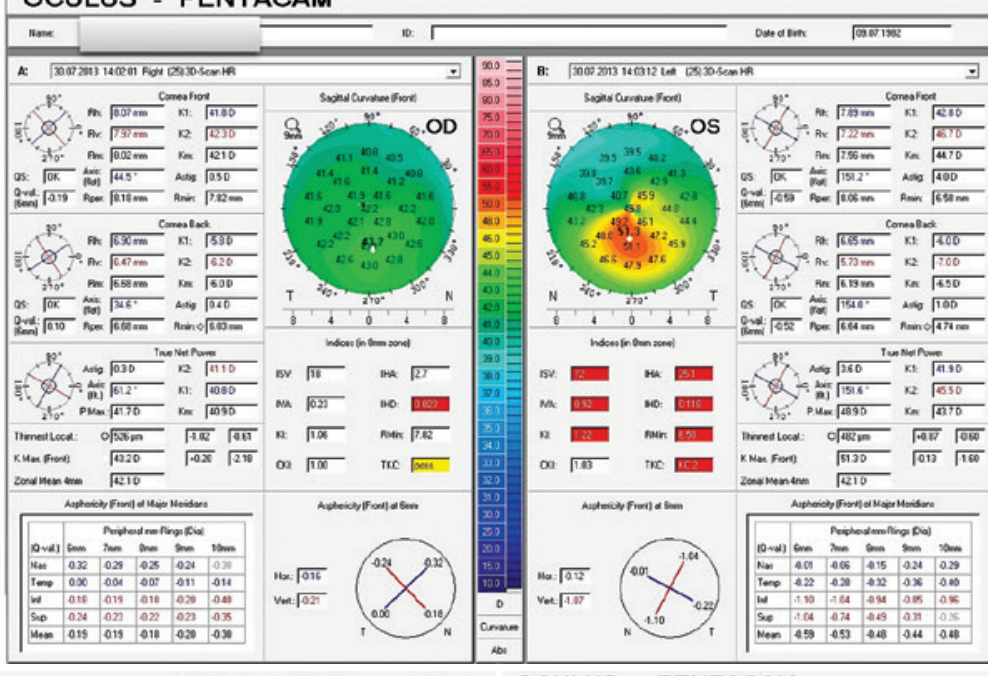

OCULUS - PENTACAM

Belin / Ambrósio Enhanced Ectasia
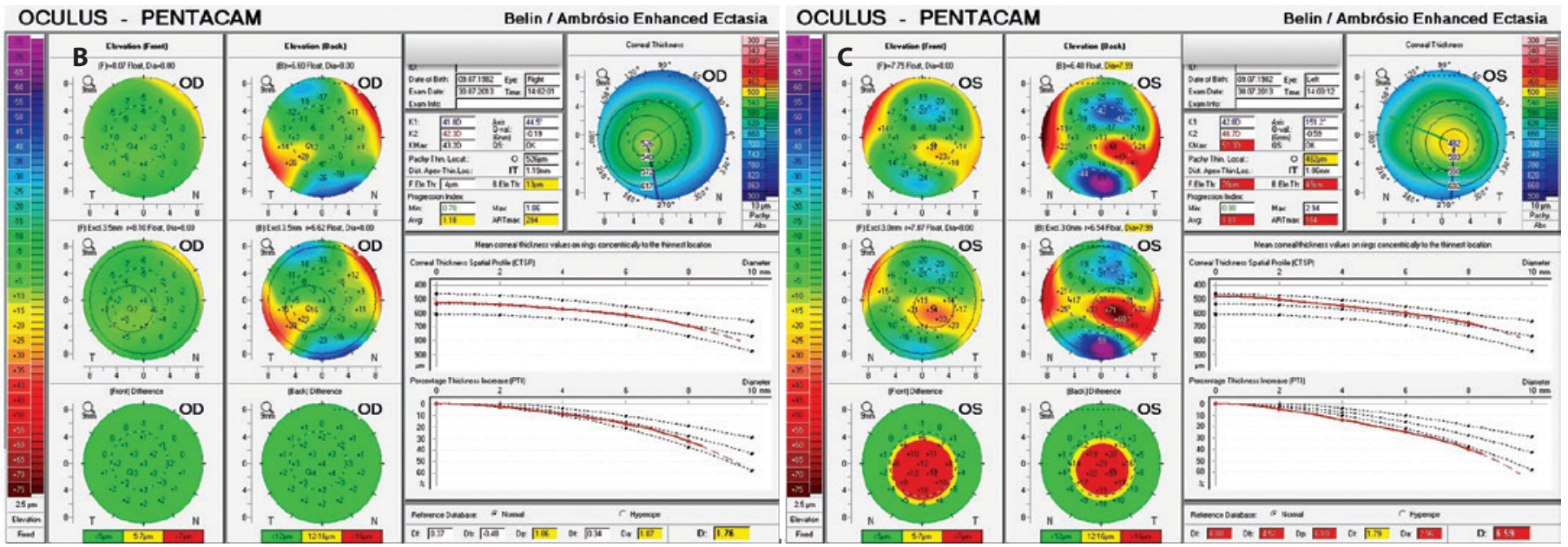

Figure 1. A) Sagittal curvature maps demonstrating inferior steepening in both eyes. The right eye was diagnosed as forme fruste keratoconus (FFKC) and the left eye as keratoconus (KC) stage 2. B) Pentacam ${ }^{\ominus}$ Belin/Ambrósio Enhanced Ectasia Display (BAD-D) in the right eye revealing abnormal values for posterior elevation and thickness distribution. C) Penta$\mathrm{cam}^{\oplus} \mathrm{BAD}-\mathrm{D}$ in the left eye revealing abnormal values for posterior elevation and thickness distribution. 
A

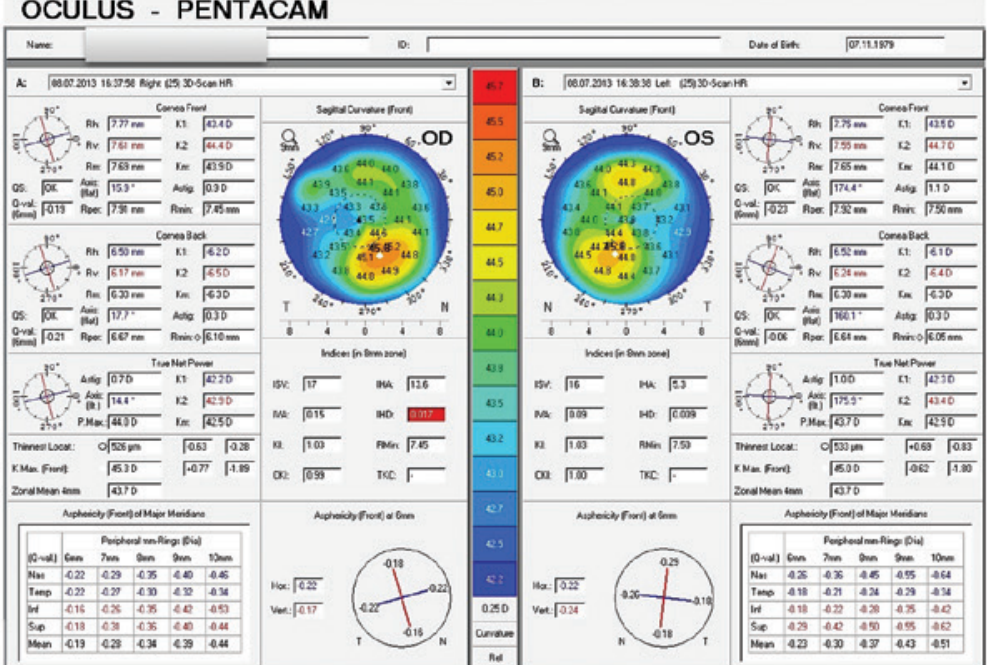

OCULUS - PENTACAM

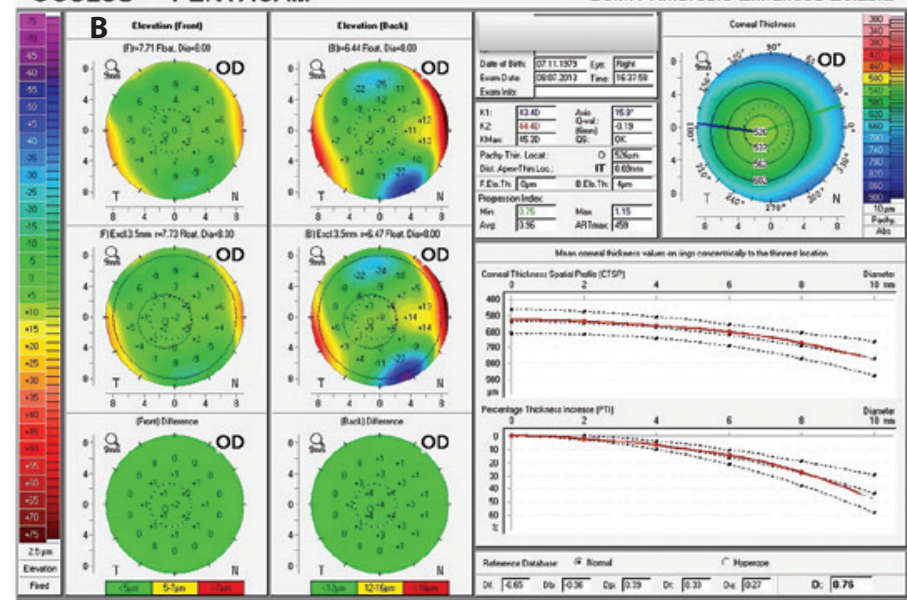

OCULUS - PENTACAM

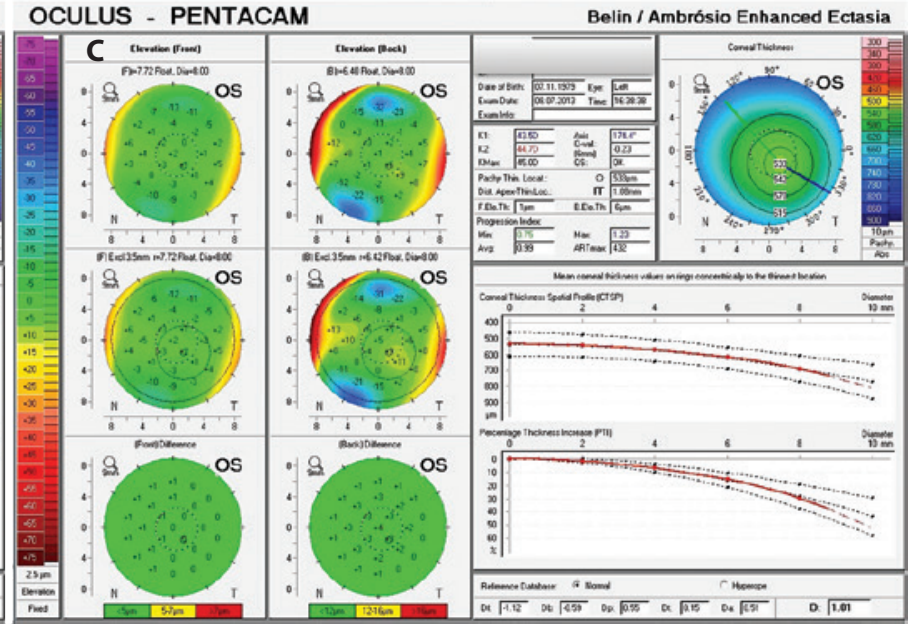

Figure 2. A) Sagittal curvature maps from a soft contact lens wearer patient demonstrating inferior steepening in both eyes. B) Pentacam ${ }^{\circledR}$ Belin/Ambrósio Enhanced Ectasia Display (BAD-D) in the right eye of a patient with contact lens-induced corneal warpage demonstrating normal anterior and posterior curvature and a normal thickness distribution. C) Pentacam BAD-D in the left eye of a patient with contact lens-induced corneal warpage demonstrating normal anterior and posterior curvature and a normal thickness distribution.
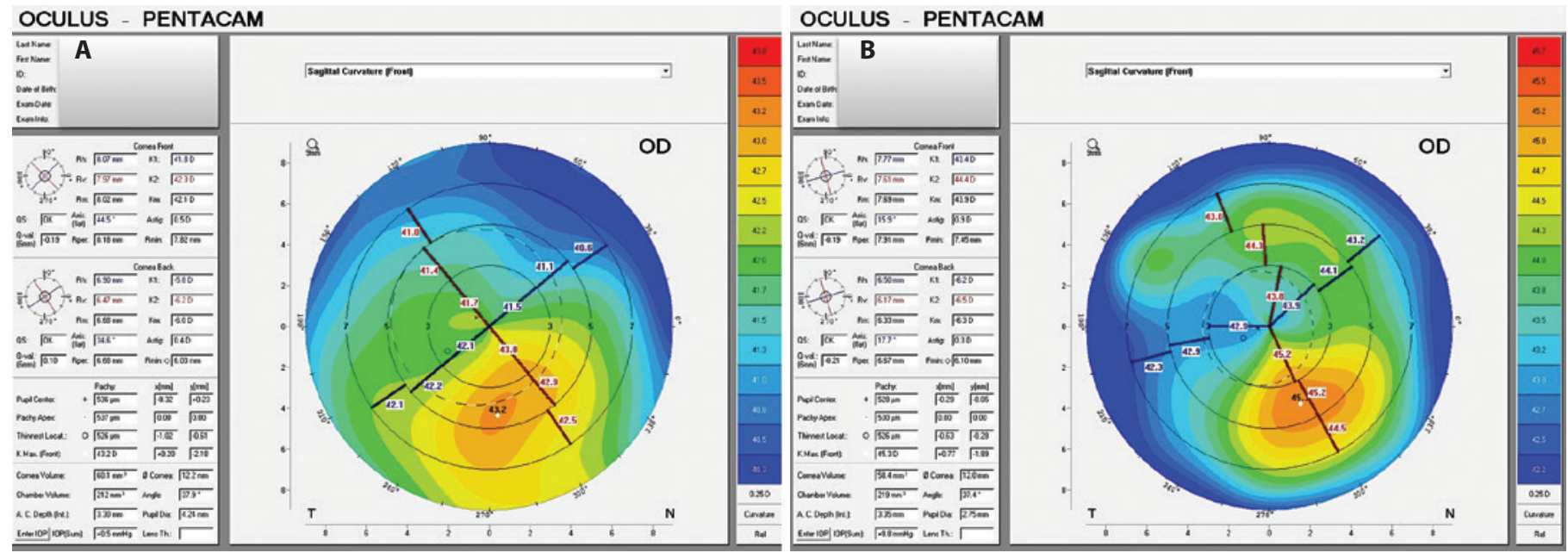

Figure 3. Sagittal curvature maps demonstrating the similarity of anterior corneal surface alterations between the two cases. A) First case; forme fruste keratoconus (FFKC). B) Second case; contact lens-induced corneal warpage. 


\section{DISCUSSION}

Many candidates for keratorefractive surgery are contact lens wearers. Contact lens-induced corneal warpage may mimic the presentation of mild cases of keratoconus (or FFKC) during preoperative topographic evaluation. Interestingly, abnormal corneal topography is the most important risk factor for post-LASIK progressive keratectasia ${ }^{(9)}$. However, in our cases, corneal topographies demonstrated patterns suspicious for keratoconus in two patients with completely distinct clinical diagnoses (Figure $3 \mathrm{~A}$ and B). The first case was a patient with corneal ectasia requiring a keratoconus therapeutic approach. The second case was a patient with contact lens-induced corneal warpage that may have benefited from keratorefractive surgery.

Scheimpflug corneal tomography is effective in detecting very mild ectasia prior to obvious changes to the front surface curvature ${ }^{(6)}$. However, objective indices derived from elevation, pachymetry, and curvature should also be considered to improve the utility of Scheimpflug corneal tomography data ${ }^{(5)}$. Pentacam ${ }^{\circledR}$ BAD combines elevation-based and pachymetric corneal evaluations. This display provides a comprehensive refractive surgical screening tool for identifying patients at a risk of postoperative ectasia.

The ability to image the posterior surface in addition to the anterior corneal surface, thereby providing a three-dimensional image of the cornea, enables keratoconic corneas to be distinguished from corneas without ectasia. Advanced tomographic analysis provides an enhanced diagnostic approach for corneal warpage on the basis of the thickness distribution and elevation data. Corneal warpage was confirmed after discontinuing contact lens wearer and topographic follow-up.

\section{CONCLUSION}

Corneal tomography data from Pentacam ${ }^{\circledR}$ enables representation of front and back elevation and pachymetric map reconstruction. The use of BAD-D provides a comprehensive keratoconus screening approach ${ }^{(10)}$. This software enabled us to accurately evaluate two cases with very similar topographies but distinct clinical diagnoses: forme fruste keratoconus and contact lens-induced corneal warpage. As the time to stabilization of contact lens-induced corneal warpage may be highly variable, tomographic evaluation has particular utility in identifying good candidates for refractive surgery.

\section{REFERENCES}

1. Rabinowitz YS. Keratoconus. Survey of ophthalmology. 1998;42(4):297-319.

2. Ambrosio R Jr, Belin MW. Imaging of the cornea: topography vs tomography. J Refract Surg. 2010;26(11):847-9

3. Belin MW, Khachikian SS. An introduction to understanding elevation-based topography: how elevation data are displayed - a review. Clin Experiment Ophthalmol. 2009; 37(1):14-29.

4. Correia FF, Ramos I, Lopes B, Salomão MQ, Luz A, Correa RO, Belin MW, Ambrosio R $\mathrm{Jr}$. Topometric and tomographic indices for the diagnosis od keratoconus. Int J Kerat Ect Cor Dis. 2012;1(2):92-9.

5. Belin MW, Ambrosio R. Scheimpflug imaging for keratoconus and ectatic disease. Indian J Ophthalmol. 2013;61(8):401-6.

6. Ambrosio R Jr, Randleman JB. Screening for ectasia risk: what are we screening for and how should we screen for it? J Refract Surg. 2013;29(4):230-2.

7. Schornack M. Hydrogel contact lens-induced corneal warpage. Cont Lens Anterior Eye. 2003;26:153-9.

8. Tsai PS, Dowidar A, Naseri A, McLeod SD. Predicting time to refractive stability after discontinuation of rigid contact lens wear before refractive surgery. J Cat Refract Surg. 2004;30:2290-4.

9. Randleman JB, Trattler WB, Stulting RD. Validation of the Ectasia Risk Score System for preoperative laser in situ keratomileusis screening. Am J Ophthalmol. 2008;145:813-8.

10. Ambrosio R, Jr., Caiado AL, Guerra FP, et al. Novel pachymetric parameters based on corneal tomography for diagnosing keratoconus. J Refract Surg. 2011;27:753-8. 